STUDI

FRANCESI

\section{Studi Francesi}

Rivista quadrimestrale fondata da Franco Simone

160 (LIV | I) | 2010

II simbolismo. Nomi, aspetti, momenti. Studi in memoria di Ivos Margoni

\title{
Aliscans, Texte établi par Claude Régnier, Présentation et notes de Jean Subrenat, Traduction revue par Andrée et Jean Subrenat
}

\section{Maria Colombo Timelli}

\section{(2) OpenEdition}

Journals

Édition électronique

URL : http://journals.openedition.org/studifrancesi/7126

DOI : $10.4000 /$ studifrancesi. 7126

ISSN : 2427-5856

Éditeur

Rosenberg \& Sellier

Édition imprimée

Date de publication : 1 avril 2010

Pagination : 120

ISSN : 0039-2944

Référence électronique

Maria Colombo Timelli, «Aliscans, Texte établi par Claude Régnier, Présentation et notes de Jean Subrenat, Traduction revue par Andrée et Jean Subrenat », Studi Francesi [En ligne], 160 (LIV | I) | 2010, mis en ligne le 30 novembre 2015, consulté le 13 janvier 2021. URL : http://journals.openedition.org/ studifrancesi/7126; DOI : https://doi.org/10.4000/studifrancesi.7126

Ce document a été généré automatiquement le 13 janvier 2021.

\section{(c) (i) (9)}

Studi Francesi è distribuita con Licenza Creative Commons Attribuzione - Non commerciale - Non opere derivate 4.0 Internazionale. 


\title{
Aliscans, Texte établi par Claude Régnier, Présentation et notes de Jean Subrenat, Traduction revue par Andrée et Jean Subrenat
}

\author{
Maria Colombo Timelli
}

\section{RÉFÉRENCE}

Aliscans, Texte établi par Claude RÉGNIER, Présentation et notes de Jean SUBRENAT, Traduction revue par Andrée et Jean SUBRENAT, Paris, Honoré Champion, 2007 («Champion Classiques - Moyen Âge», 21), pp. 631.

1 Ce poème anonyme de la geste de Guillaume d'Orange, composé à l'extrême fin du XII siècle, met en scène la guerre traditionnelle qui oppose Chrétiens et Sarrasins, doublée par une série de conflits familiaux; vis-à-vis d'un roi de France qui a perdu toute autorité, s'affirment la solidarité interne au lignage d'Aymeri de Narbonne et la valeur personnelle de quelques figures de premier plan: Vivien d'abord, qui ouvre et clôt le poème, Renouart et son célèbre «tinel», Guillaume naturellement; mais aussi quelques femmes: Guibourc, soeur de Rainouart et femme de Guillaume, Aélis, la fille du roi Louis qui deviendra l'épouse de Rainouart.

2 Cette édition-traduction est le fruit du travail de deux spécialistes. De l'édition du regretté Claude Régnier («CFMA», 1990) sont repris non seulement le texte et les notes (avec de rares corrections, surtout suggérées par les comptes rendus de D. Mac Millan et d'A. Brasseur), mais une grande partie de l'Introduction: le commentaire philologique (pp. 12-14), la note sur l'établissement du texte (pp. 14-17), l'étude linguistique (pp. 17-23), la quasi-totalité de l'analyse de la versification (pp. 23-28), la discussion de la date (pp. 28-29). Jean Subrenat a fourni, quant à lui, la présentation des 13 manuscrits et des quelques fragments, s'étendant de la fin du XII à la première 
moitié du

XIV siècle (pp. 9-12), et surtout l'étude des personnages et des dynamiques familiales dans la chanson de geste (pp. 30-48), ainsi que l'analyse synthétique du contenu (pp. 48-53); la bibliographie, bien que sélective, a été mise à jour (pp. 55-60). La traduction, en prose, est une version révisée de celle que le même Jean Subrenat et Bernard Guidot avaient publiée chez Champion en 1993 («Traductions des CFMA»).

3 Si l'édition est l'œuvre d'un maître, la traduction est, elle aussi, remarquable; et si Jean et Andrée Subrenat ont pu s'accorder quelques libertés avec le poème, ce qui est non seulement inévitable, mais souvent indispensable, on leur sera particulièrement reconnaissant d'avoir fourni aussi un glossaire renouvelé par rapport à celui de Régnier (pp. 565-603), qui permet soit de retrouver le sens littéral des mots, soit de nuancer la traduction proposée. L'index des noms propres est dédoublé: personnages (pp. 605-629) et lieux (pp. 621-629).

4 Nous avons là - on l'aura compris - une édition complète, qui dépasse en partie l'œuvre de Claude Régnier par des compléments d'information; il en est ainsi pour les annexes, où sont réunis la liste des vers empruntés à d'autres manuscrits (que Régnier avait signalés par des astérisques, pp. 521-523), la liste des corrections (tirée, celle-ci, de l'édition de Régnier, avec une intégration suggérée par A. Brasseur, pp. 525-539), et surtout pour les 10 appendices, où sont reproduits des passages significatifs tirés d'autres manuscrits: laisses supplémentaires, développements, voire épisodes ajoutés, qui confirment non seulement le phénomène général de la «variance» des textes médiévaux, mais parfois déjà une première réception du texte (pp. 541-563). 